ISSN 1112-9867

Available online at

http://www.jfas.info

\title{
STUDY OF ANTIOXIDANT ACTIVITY AND FREE RADICAL SCAVENGING POWER OF PHYSALIS ALKEKENGI FLOWER EXTRACT
}

M. M. Nemat Shahi*1 ${ }^{1}$ A. H. Elhami $\operatorname{Rad}^{2}$, N. Nemat Shahi ${ }^{3}$, A. Pedram Nia ${ }^{2}$, H. Estiri $^{2}$

${ }^{1}$ Sabzevar Branch, Islamic Azad University, Sabzevar, Iran.

${ }^{2}$ Department of Food Science and Technology, Sabzevar Branch, Islamic Azad University, Sabzevar,Iran.

${ }^{3}$ Faculty of Basic Sciences, Ferdowsi University of Mashhad, Mashhad, Iran

Published 11 June 2016

\begin{abstract}
According to the undesirable effects of many chemical preservatives in food products such as oilseed extraction industry, the possibility of substituting these materials with effective compounds of herbal plants have been considered by the researchers. In this study, at first, the Physalis Alkekengi flower extract was extracted by using maceration method with methanol. The Phenolic compounds and the amount of free radical scavenging activity of the flower extract were investigated in different concentrations (200, 400, 600, 800 and $1000 \mathrm{ppm})$, respectively by Folin-Ciocalteu method and DPPH test and were compared with the synthetic antioxidant activity (BHT) at $200 \mathrm{ppm}$. The results showed a significant difference between different concentrations of Physalis Alkekengi flower extract, in terms of the rate of Phenolic compounds and free radical scavenging activity of flower extract $(\mathrm{p}<0.05)$. In general, the results of this study showed that the methanol extract of Physalis Alkekengi flower, as a source of cheap and available natural antioxidant, after conducting supplementary experiments can be used in food industry.
\end{abstract}

Keywords: Physalis Alkekengi flower, Free radical scavenging power, Natural antioxidants, Phenolic compounds.

Author Correspondence, e-mail: m.nematshahi67@gmail.com doi: http://dx.doi.org/10.4314/jfas.v8i2s.39 


\section{INTRODUCTION}

Today, the use of different synthetic combinations as a preservative is one of the problems of food industry that the potential risks of each of these compounds to human health has been proved. In oil industry, there are several ways to prevent oxidation that one of these items is adding synthetic antioxidants for oil oxidation stability. But, according to the undesirable effects of synthetic antioxidants such as carcinogenic and mutagenic effects in human body, gradually was eliminated from the list of consumable antioxidants. Therefore, studying and investigating the resource of natural antioxidants in order to replace the synthetic compounds seems to be necessary $[1,2]$. Investigating the conducted studies about the effect of natural antioxidants in edible oils indicate that natural antioxidants besides the stability of edible oils, can cause an increase in their nutritional value [3]. Husk tomato plant or doll behind the scenes with the scientific name of (Physalis Alkekengi) and other local name of love in a cage is a gramineous plant, perennial and with creeping stem and an angular and straight stem [4]. The fruit of this plant contains Fyzalyzyn, alkaloids, lycopene, glucocorticoids, alcoholic materials and large amounts of vitamin C. These substances accelerate the excretion of uric acid, so, are used in kidney disorders and urinary ducts, gout and rheumatism. This extract also has anti-inflammatory, anti-mitosis, antibacterial properties, causes menstruation and treating syphilis and malaria [5-9] . Several studies in the field of the extraction of natural antioxidants from medicinal plants have been done that some of them will be referred in the following. Mirzaei et al., 2011, investigated the antioxidant properties and total phenol of hydro-alcoholic extract of Sisymbrium irio, plantain, Carum copticum, coriander, fenugreek by using maceration method. Hydro-alcoholic extracts of five mentioned herbs were examined in all the models and the highest antioxidant activity was related to plantain plant [10]. Ahmadvand et.al.2012, have studied the antioxidant properties of Hydro-alcoholic extracts and essence of the Vitex Pseudo-negundo. Obtain results showed that the total antioxidant capacity of hydro-alcoholic extract and essence of Vitex Pseudo-negundo, are respectively $1.76 \pm 0.25$ and $2.12 \pm 0.6$ and the amount of phenol in hydro-alcoholic extract and the essence of Vitex Pseudo-negundo is respectively $22 \pm 2$ and $133.11 \pm 3$, the amount of flavonoid in hydro-alcoholic extract and essence of Vitex leaf, is respectively $18 \pm 1$ and $5.5 \pm 4$. The amount of $\mathrm{IC}_{50}$ in hydro-alcoholic extract, essential oils and butyl hydroxy toluene (BHT), as a positive control is 
respectively $224.75 \pm 4.52,133.00 \pm 33$ and 3.88 \pm 1 (Micrograms per milliliter) [11]. Eyouqi et al (2009), have investigated the antioxidant activity of dill essence by measuring the values of Peroxide and Thiobarbituric acid in soybean oil. They concluded that dill essence has the ability to prevent the production of primary and secondary oxidation products in the raw soybean oil at the concentration of $6.0 \mathrm{mg}$ per $\mathrm{ml}$ which is approximately equivalent to BHA chemical anti-oxidation at the concentration level of $1.0 \mathrm{mg}$ per $\mathrm{ml}$. Based on the report of researchers, dill essence can act as a natural antioxidant and can be added to foodstuffs after supplementary experiments [12].

The aim of this research is to evaluate the antioxidant properties of Physalis Alkekengi flower through measuring the phenolic compounds and the rate of free radical scavenging activity of the flower extract in different concentrations and comparing it with the synthetic antioxidant power (BHT) at $200 \mathrm{ppm}$, in order to replace the synthetic preservatives by natural antioxidants.

\section{MATERIALS AND METHODS}

\section{The preparation of Physalis Alkekengi flower extract}

Husk tomato plant flowers were prepared from the local market of Sabzevar city and form one variety. For this purpose, the waste materials were separated at first and after washing, were dried in the shade and at a temperature of $25^{\circ} \mathrm{C}$, and then, with the mill (Kenwood, model $100 \mathrm{CG}$ ) were completely powdered and the obtained powder, after sifting was mixed with methanol solvent to prepare the extract based on maceration method with the ratio of 1:10 (weight-volume) and located on the magnetic stirrer at a speed of 250 revolutions per minute for 24 hours at ambient temperature and then was smoothed by No.1 Whatman filter and under vacuum conditions. The resulting solution was concentrated by a rotary evaporator (model Laborata 4000 ) at $35^{\circ} \mathrm{C}$ and finally the extract was dried by drying chamber under vacuum at $40^{\circ} \mathrm{C}$ and until the time of use, was placed in an enclosed container and impervious to air at $4^{\circ} \mathrm{C}$ [13].

\section{Measuring the total amount of phenolic compounds of Physalis Alkekengi flower extract}

To measure the total amount of phenolic compounds of the Physalis alkekengi flower extract, firstly the standard solution of the Physalis Alkekengi flower extract will be prepared with a solvent which the extraction is done by it and (methanol) with different concentrations in the range 
of 300, 400, 500, 600 and $700 \mathrm{ppm}$ and the control sample. Then, $0.5 \mathrm{ml}$ of each of the dilutions was transferred into a test tube wrapped with foil. Then, $2.5 \mathrm{ml}$ of Folin-Ciocalteu reagent 0.2 normality (In proportion of 1 to 10 diluted with distilled water) was added to each tube and was intensely stirred for 30 seconds by the tube stirrer. Then, $2 \mathrm{ml}$ of sodium carbonate solution (7.5\%) was added to the tubes and after stirring for 30 seconds, it was kept in the dark for an hour at room temperature. The absorption of each of the samples in the wavelength of $765 \mathrm{~nm}$ was read out by the spectrophotometer device. The amount of phenolic compounds was determined by the linear regression equation which is obtained from the calibration curve of Gallic acid as a standard $\mathrm{Y}=0.0121 \mathrm{X}-0.0309, \mathrm{R}^{2}=0.9679$ based on the Gallic acid percentage. In the regression equation of the calibration curve of Gallic acid, $\mathrm{Y}$ is the absorption rate that was read at a wavelength of $765 \mathrm{~nm}$ and $\mathrm{X}$ is the concentration of phenolic compounds based on $\mathrm{mg} / \mathrm{l}$ [14].

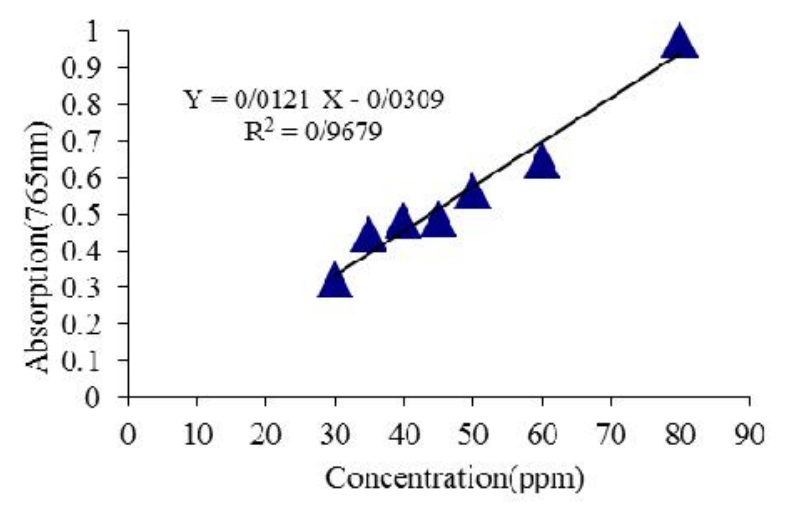

Fig.1. Standard curve of Gallic acid for determining the total amount of phenolic compounds of the Physalis Alkekengi flower extract.

\section{Measuring the free radical scavenging activity (DPPH) of Physalis Alkekengi flowers}

Antioxidant activity evaluation was measured by investigating the 2, 2-diphenyl-1-picrylhydrazyl (DPPH) free radical scavenging power. For this purpose, at first, different dilutions of the dried extract of Physalis Alkekengi flowers including 300, 400, 500, 600 and 700 ppm and also, the control sample with methanol solvent were prepared. The stages briefly are as follows. $2 \mathrm{ml}$ of each of the dilutions was transferred into the test tube and then $2 \mathrm{ml}$ of reagent 2 , 2-diphenyl-1-picrylhydrazyl $(0.004 \%)$ was added to each tube and was completely stirred and was kept in the dark for 90 minutes at room temperature and then the absorption of the samples was 
read out in the wavelength of $517 \mathrm{~nm}$ by the spectrophotometer device. The free radical scavenging power was calculated by using Equation 1, [11].

$$
I \%=\left(\frac{A_{\text {Blank }}-A_{\text {Sample }}}{A_{\text {Blank }}}\right) \times 100
$$

In this equation, $A_{B l a n k}$ is the optical density of the control sample (without extract) and $A_{\text {Sample }}$ is the optical density of different concentrations of the extract. It should be mentioned that in this experiment, 200 ppm of synthetic antioxidant (BHT) was used for comparison.

\section{The statistical analysis}

In this study, the completely randomized design was used. Data was analyzed by using SAS software. Comparison of the mean of the data was performed by using the least significant difference (LSD) test at the statistical level of 95\%. Microsoft Excel, 2003 was used for drawing diagrams.

\section{RESULTS AND DISCUSSION}

\section{The amount of phenolic compounds of the Physalis Alkekengi flower extract}

With the consideration of phenols and phenolic compounds and their wide presence in foods and herbal products and their considerable antioxidant properties, their measurement and evaluation were investigated in this study. The analysis of variance of the impact of antioxidant compounds concentration on the rate of phenolic compounds has been reported in table 1 . The results showed that the impact of antioxidant compounds concentration on the rate of phenolic compounds of Physalis alkekengi flower extract was significant $(\mathrm{P}<0.05)$ at statistical level of $5 \%$. 
Table1. Analysis of variance of the impact of antioxidant compounds concentration on the amount of phenolic compounds.

\begin{tabular}{|c|c|c|c|c|}
\hline $\begin{array}{c}\text { Sources of } \\
\text { change }\end{array}$ & $\begin{array}{c}\text { Degree of } \\
\text { freedom }\end{array}$ & $\begin{array}{c}\text { Average of } \\
\text { squares }\end{array}$ & $\begin{array}{c}\text { Amount of } \\
\mathrm{F}\end{array}$ & $\mathrm{P}$ \\
\hline $\begin{array}{c}\text { Antioxidant } \\
\text { compounds } \\
\text { concentration }\end{array}$ & 5 & 326.927 & 24973.3 & 0.0000 \\
\hline Error & 6 & 0.013 & - & - \\
\hline Total & 11 & - & - & - \\
\hline C.V & 0.42 & - & - & - \\
\hline
\end{tabular}

Due to the meaningful impact $(\mathrm{p}<0.05)$ of antioxidant compounds concentration on the amount of phenolic compounds (Table 1), the majority of phenolic compounds with a meaningful difference was observed at 1000ppm concentration of Physalis Alkekengi flower extract (Figure 2). Also, the results showed that the lowest amount of phenolic compounds was observed in the control sample. About the Physalis Alkekengi flower extract, as can be seen, by increasing the extract concentration from 200 to $1000 \mathrm{ppm}$, the rate of phenolic compounds contained in extract is increased that this matter leads to an increase in the antioxidant properties.

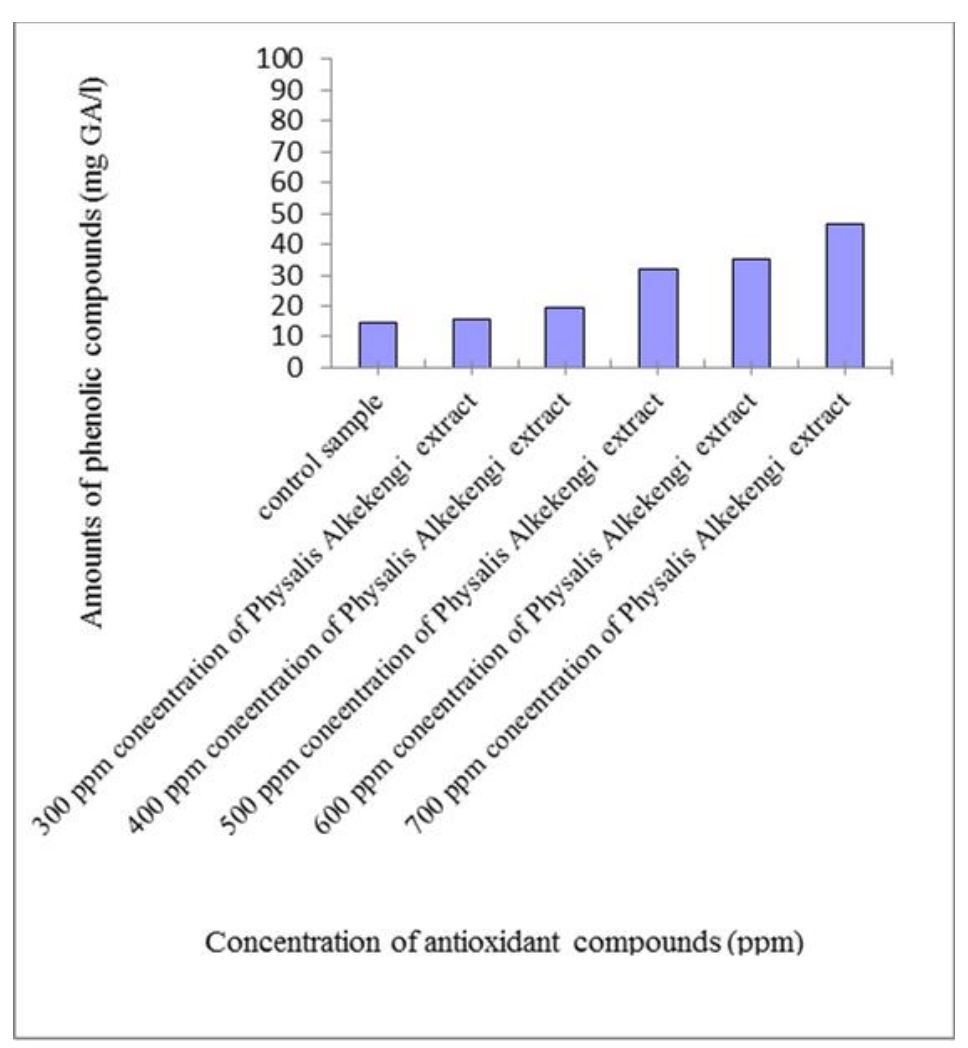

Fig.2. Changes in the amount of phenolic compounds in different concentrations of Physalis Alkekengi flower extract. 


\section{Radical scavenging activity of Physalis Alkekengi flower extract}

Results of the analysis of variance of the impact of type and antioxidant compounds concentration (Natural antioxidants of Physalis Alkekengi flower and synthetic antioxidants BHT) on the free radical scavenging power has been reported in table 2 . The results showed the significant impact of the type and the antioxidant compounds concentration at the statistical level of $5 \%$ on the free radical scavenging activity of Physalis Alkekengi flower $(\mathrm{p}<0.05)$.

Table2.The analysis of variance of the impact of type and antioxidant compounds concentration on the free radical scavenging power.

\begin{tabular}{|c|c|c|c|c|}
\hline Sources of change & $\begin{array}{c}\text { Degree of } \\
\text { freedom }\end{array}$ & $\begin{array}{c}\text { Average of } \\
\text { squares }\end{array}$ & $\begin{array}{c}\text { Amount of } \\
\text { F }\end{array}$ & P \\
\hline $\begin{array}{c}\text { Antioxidant } \\
\text { compounds } \\
\text { concentration }\end{array}$ & 6 & 1553.98 & 0.24162 & 0.0000 \\
\hline Error & 7 & 0.06 & - & - \\
\hline Total & 13 & - & - & - \\
\hline C.V & 0.55 & - & - & - \\
\hline
\end{tabular}

According to the meaningful impact of $(\mathrm{p}<0.05)$ antioxidant compounds concentration on the free radical scavenging activity (Table 2), the maximum rate of radical scavenging power was observed with a significant difference in the 200ppm concentration of synthetic antioxidant (BHT) (Figure 3). Also, the results indicated that, the most radical scavenging power between difference concentrations of the extract was observed in 700 ppm concentration. 


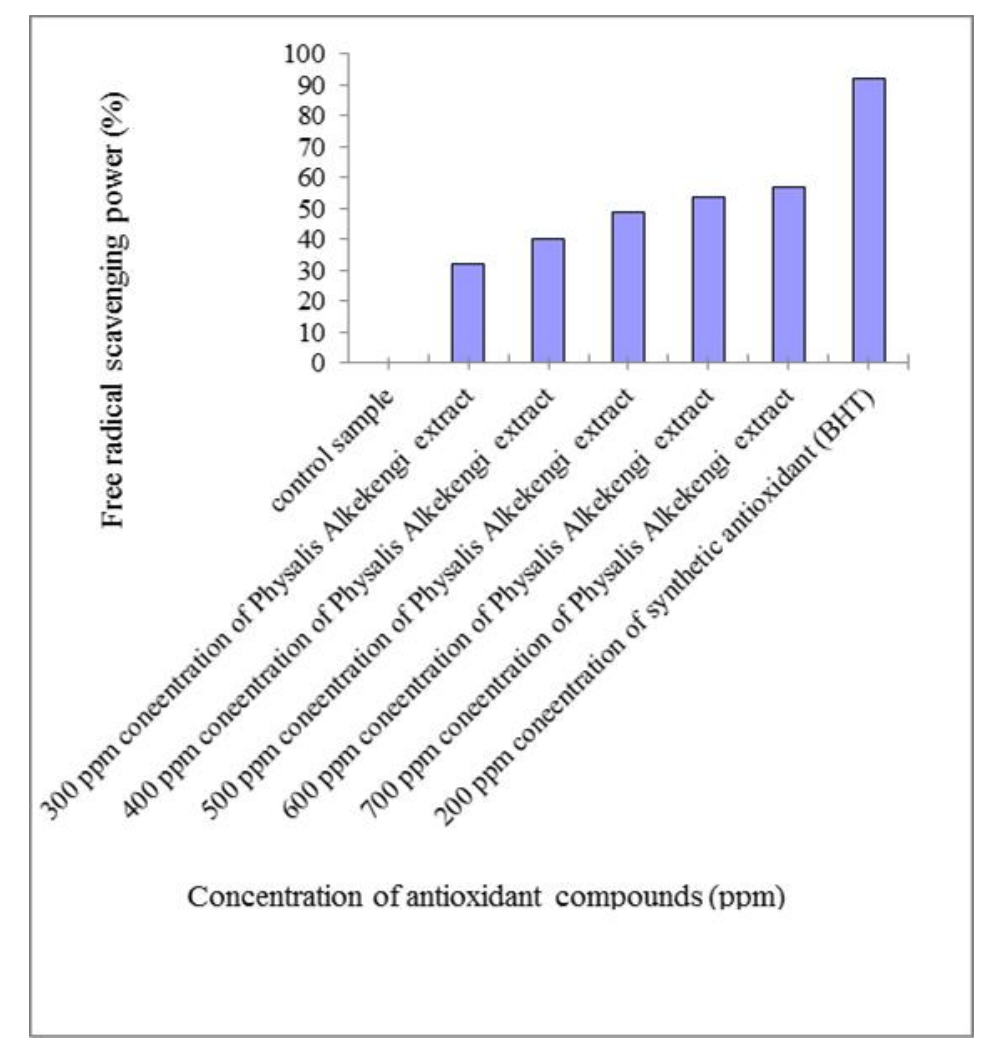

Fig.3. Changes of the free radical scavenging activity in different concentrations of Physalis Alkekengi flower extract and comparing it with the synthetic antioxidants (BHT).

In confirming the results of this research, several studies have been conducted by the researchers. In a study, Ahmadvand et.al.(2012). have examined the antioxidant properties of hydro-alcoholic extract and the essential oil of Vitex Pseudo-Negundo plant. They reported the total antioxidant capacity of hydro-alcoholic extract and the essence of Vitex Pseudo-negundo which are respectively $1.76 \pm 0.25$ and $2.12 \pm 0.6$ and the amount of phenol in hydro-alcoholic extract and the essence of Vitex Pseudo-negundo are respectively $22 \pm 2$ and 133.11 \pm 3 [11].

In a similar study, Unver et.al (2009) investigated the antioxidant activity and the total phenol content of methanolic extract of a number of plants and concluded that there is a direct relationship between the amount of total phenols and the antioxidant activity of the extract of these plants, so that in this regard, the plant of Mentha Piperita showed the top rate of total phenols (493 mg equivalent to Gallic acid per gram) and the high antioxidant activity ( $\mathrm{IC}_{50}$ equal to $0.23 \mathrm{mg} / \mathrm{ml}$ ) and the plant of Capparis Ovate showed the low rate of total phenols (185 mg equivalent to Gallic acid per gram) and low antioxidant activity ( $\mathrm{IC}_{50}$ equal to $\left.4.08 \mathrm{mg} / \mathrm{ml}\right)[16]$. 


\section{CONCLUSION}

In oil industry, to prevent oxidation, synthetic antioxidants such as BHT are used for oil oxidative stability. But, according to the undesirable effects of synthetic antioxidants on human's body, they were gradually eliminated from the list of consumable antioxidants. Therefore, studying and investigating the sources of natural antioxidants seems to be necessary in order to replace it with synthetic compounds. Therefore, in this study, in order to introduce the use of natural antioxidants, the antioxidant power of the extracted sap from Physalis Alkekengi flowers was examined in different concentrations by the Folin-Ciocalteu method and DPPH test and ultimately it was compared with the synthetic antioxidant activity (BHT) at 200ppm. In general, the results obtained from investigating the antioxidant power of different concentrations of Physalis Alkekengi flower extract, showed that 700ppm concentration of this extract has the highest antioxidant properties and consequently the highest radical scavenging activity than other concentrations of this extract.

\section{REFERENCES}

[1] Taha Nejad, M , Barzegar, M , Sahari, M , Naghdibari, h.(2012). Evaluating the Anti-radical activity of Malva Sylvestris extract and its application in oil system, Journal of Medicinal Plants, eleventh year, second period, Serial number of Forty-Two.

[2] Lanez T, Henni M. Antioxidant activity and superoxide anion radical interaction with 2(ferrocenylmethylamino) benzonitrile and 3-(ferrocenylmethylamino) benzonitrile. J Iran Chem Soc. 2016, doi: 10.1007/s13738-016-0891-1

[3] Bera D, Lahiri, D \& Nag, A. (2006). Studies on a natural antioxidant for stabilization of edible oil and comparison with synthetic antioxidants. Journal of Food Engineering,74, 542-545.

[4] Changizi Ashtiani, S , Zareei, A, Shariati, M , Jabbari, A , Ghasemi, H .(2011). The impact of the alcoholic extract of Physalis Alkekengi plant on some plasma biochemical factors in rat. Scientific and research journal of University of Medical Sciences, Arak.14 (5):18-25.

[5] Zareei A, Shariati, M, Shekarfofroush, Sh , Changizi Ashtiani, S , Rasekh, F.(2011). A quick review on the impact of using the extract of Physalis Alkekengi plant on the physiological function of tissues of the body. Scientific and research journal of University of Medical Sciences, Arak. 15(7):104-94. 
[6] Rebiai A, Lanez T, Belfar M. Total polyphenol contents, radical scavenging and cyclic voltammetry of Algerian propolis. Int J Pharm Pharm Sci, 2014, 6(1), 395-400

[7] Boubekri C, Lanez T, Djouadi A. A comparative study on antioxidant activities and phenolic contents of five algerian eggplant cultivars. St. Cerc. St. CICBIA 2015, 16 (1), $29-46$.

[8] Rebiai A, Lanez T, Belfar M. In vitro Evaluation of Antioxidant Capacity of Algerian Propolis by Spectrophotometrical and Electrochemical Assays. International Journal of Pharmacology 2011, 7(1), 113-118, doi: 10.3923/ijp.2011.113.118.

[9] Khelef A, Lanez T. In vitro assays of the antioxidant activities of ferrocene derivatives bearing amine, amide or hydrazine groups. Der Pharma Chemica, 2015, 7(6),318-323

[10] Mirzaei, A , Mohammadi, J , Mirzaei, N , Mirzaei, M. (2011). Evaluating the antioxidant properties and total phenol of hydroalcoholic extract of Sisymbrium irio, plantain, Carum copticum, coriander, fenugreek, Journal of Medical Sciences University of Fasa, first year No.13. [11] Ahmadvand, H. A. H , Ekbatan Hamadani, S , Bagheri, Sh.(2012). The antioxidant properties of hydro-alcoholic extract and the essence of Vitex Pseudo-negundo , Scientific-Research Quarterly, University of Medical Sciences, Lorestan. 14(2):13-5.

[12] Eyouqi, f. Barzegar, M. Sahari, M , Nafgdibadi , H. Bahar.(2009). Investigating the antioxidant activity of Dill essence (Anethum graveolens) in soybean oil and comparing it with chemical antioxidants, Journal of Medicinal Plants ,8 (2):30.

[13] Nemat Shahi, M . (2013). Investigating the antioxidant effect of Laurus Nobilis leaf extract on the stability of canola oil during storage, the thesis of Islamic Azad University of Sabzevar, ,record number:1392.

[14] Galoburda, R, Kruma, z \& Ruze, k .(2012). Effect of Pretreatment Method on the Content of Phenolic Compunds, vitamin C and Antioxidant Activity of Dried Dill.World Academy of Sience Enginneering and Technology,64.

[15]Burits, M, Bucar, F.(2000).Antioxidant activity of Nigella sativa essential oil. Phytotheraphy Research, 14, 323-328.

[16]Unver, A, Arslan, D, Ozcan, M.M \& Akbulut, M. (2009). Phenolic content and antioxidant activity of some spices, World Appl. Sci.J.6, 373 -7. 


\section{How to cite this article:}

Nemat Shahi M M, Elhami Rad A H, Nemat Shahi N, Pedram Nia A, Estiri H. Study of antioxidant activity and free radical scavenging power of physalis alkekengi flower extract. J. Fundam. Appl. Sci., 2016, 8(2S), 547-557. 